\title{
A USER'S GUIDE TO THE ARKANSAS RURAL WATER-DELIVERY NETWORK GEOGRAPHIC INFORMATION SYSTEM (GIS) SOFTWARE
}

By Jim E. Monical

\section{U.S. GEOLOGICAL SURVEY}

Open-File Report 92-108

Prepared in cooperation with the ARKANSAS SOIL AND WATER CONSERVATION COMMISSION 


\section{U.S. DEPARTMENT OF THE INTERIOR}

MANUEL LUJAN, JR., Secretary

U.S. GEOLOGICAL SURVEY

Dallas L. Peck, Director

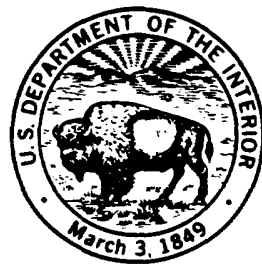

For additional information write to:

District Chief

U.S. Geological Survey 2301 Federal Office Building

700 West Capitol Avenue

Little Rock, Arkansas 72201
Copies of this report can be purchased from:

U.S. Geological Survey

Books and Open-File Reports Section Federal Center

Box 25425

Denver, Colorado 80225 


\section{CONTENTS}

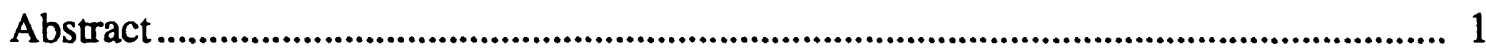

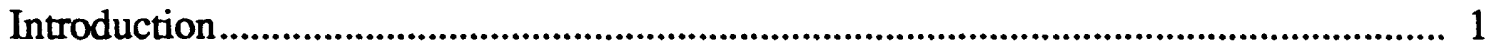

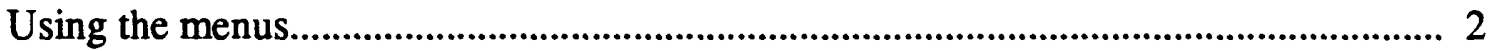

Accessing the rural water-delivery network geographic information system (GIS)

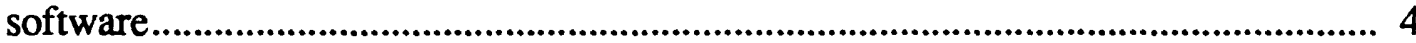

Display delivery network features ...................................................................................... 4

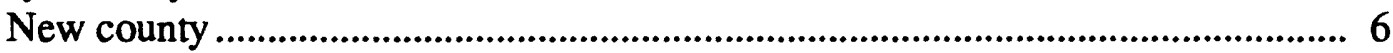

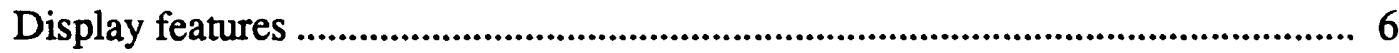

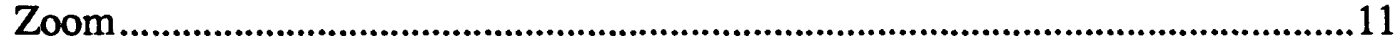

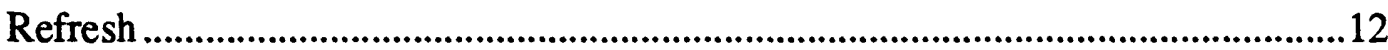

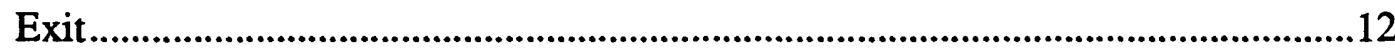

Create/update pipeline coverages ...............................................................................12

Naming conventions ...............................................................................................13

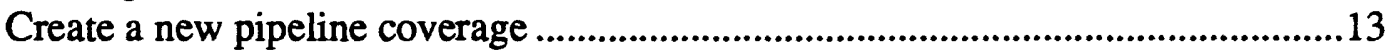

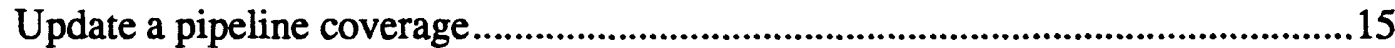

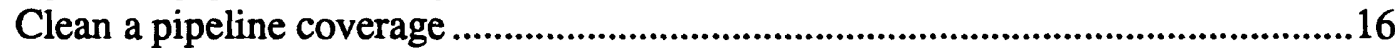

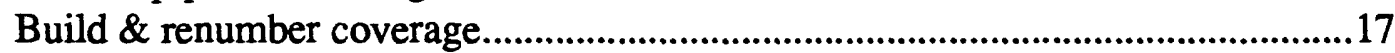

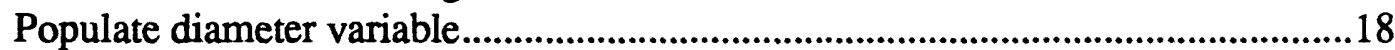

Create withdrawal coverages .......................................................................................20

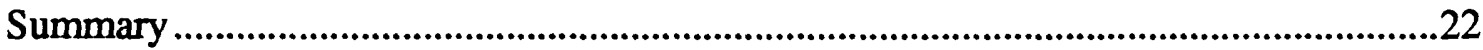

\section{ILLUSTRATIONS}

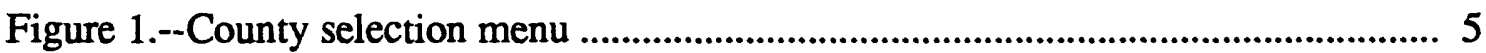

2.--Computer terminal display of Arkansas County boundary resulting from selection of Arkansas County from the County Selection menu. 


\title{
A USER'S GUIDE TO THE ARKANSAS RURAL WATER-DELIVERY NETWORK GEOGRAPHIC INFORMATION (GIS) SOFTWARE
}

\author{
By Jim E. Monical
}

\begin{abstract}
A user's guide was developed to assist users of the Rural Water-Delivery Network Geographic Information System (GIS) software. This GIS contains spatial data descriptions of the pipelines and public and municipal water-supply withdrawal points of rural water-delivery networks in the State and the software routines written to access the data.

This user's guide documents procedures and terminology used in the Rural Water Delivery Network GIS software. The software/user interface described in this guide is a series of screen menus that the user responds to with the tab key, with a carriage return, or with a mouse (a device connected to the terminal that can be moved across a flat surface to position the cursor on the screen). These menus allow the user to create, display, or update spatial data in the GIS. A representation of each menu is presented, and the responses are discussed.
\end{abstract}

\section{INTRODUCTION}

The Rural Water Delivery Network Geographic Information System was developed by the U.S. Geological Survey (USGS) in cooperation with the Arkansas Soil and WAter Conservation Commission (ASWCC). This Geographic Information System (GIS) is composed of two parts: spatial data describing the pipelines and withdrawal points of rural water networks in each county in Arkansas, and software routines written to create, display, and update these spatial data. This guide was prepared to assist users of the Rural Water Delivery Network GIS by describing and documenting the software routines that access the spatial data stored in the GIS.

The data for the rural water networks are stored in a spatial data base in several data layers called coverages. These data consist of a pipeline coverage and a withdrawal points coverage for each county. The pipeline coverages were digitized or based on a series of paper maps provided by the ASWCC. The withdrawal coverages are created from data stored in the USGS Water Use Data System (WUDS) data base.

The Rural Water Delivery Network GIS utilizes ARC/INFO ${ }^{1}$ GIS software and software routines written in Arc Macro Language (AML). The AML routines are designed to maximize system independence and minimize keyboard entry by the use of interactive screen menus. The use of screen menus limits the chance of an error being introduced through the keyboard.

1. Use of trade or firm names in this report is for identification purposes only and does not constitute endorsement by the U.S. Geological Survey. 
This guide includes a section that discusses the types of menus used, how they appear on the screen, and how selections are made from each type of menu. Another section gives a brief description of how to access the software. The rest of the guide describes the three main headings under the main menu, Display Delivery System Features, Create/Update Pipeline Coverages, and Create Withdrawal Coverages. Examples of how each menu will appear on the user on the terminal screen are given throughout the guide.

\section{USING THE MENUS}

This section will discuss some basic concepts about the types of screen menus that are used, how to make choices from these menus, and some basic terminology that is used to describe screen menus.

Screen menus are a listing of a series of choices displayed on the terminal screen. These choices can be a word, a phrase, or a number. When a menu appears on the terminal screen, the screen cursor will be positioned at one of the menu choices which will be highlighted. Selections from the list of choices are made by moving the screen cursor or crosshairs to the position that the work or phase of the desired choice occupies in the menu and performing a "pick" by either hitting a button on the mouse or entering a carriage return from the keyboard. The screen cursor may be moved with the tab key on the keyboard, and the screen crosshairs may be moved by positioning the mouse attached to the terminal. When a menu choice is "picked", visual feedback of that pick is provided by the selected menu choice becoming highlighted and blinking.

The rest of this guide will refer to the selection of a choice from a screen menu as a pick. When an example of a menu is used in this document, bold type will be used to represent text that would be highlighted on a screen menu.

Several different types of menus are used by the Rural Water Delivery Network GIS software. Pull-down menus appear as a bar across the top of the screen with each choice appearing in its own box.

\section{NEW COUNTY I DISPLAY FEATURES | ZOOM | REFRESH | EXIT}

If a choice is made from a menu bar like this, it may activate some part of the program or it may cause a submenu to be displayed with another series of choices. 


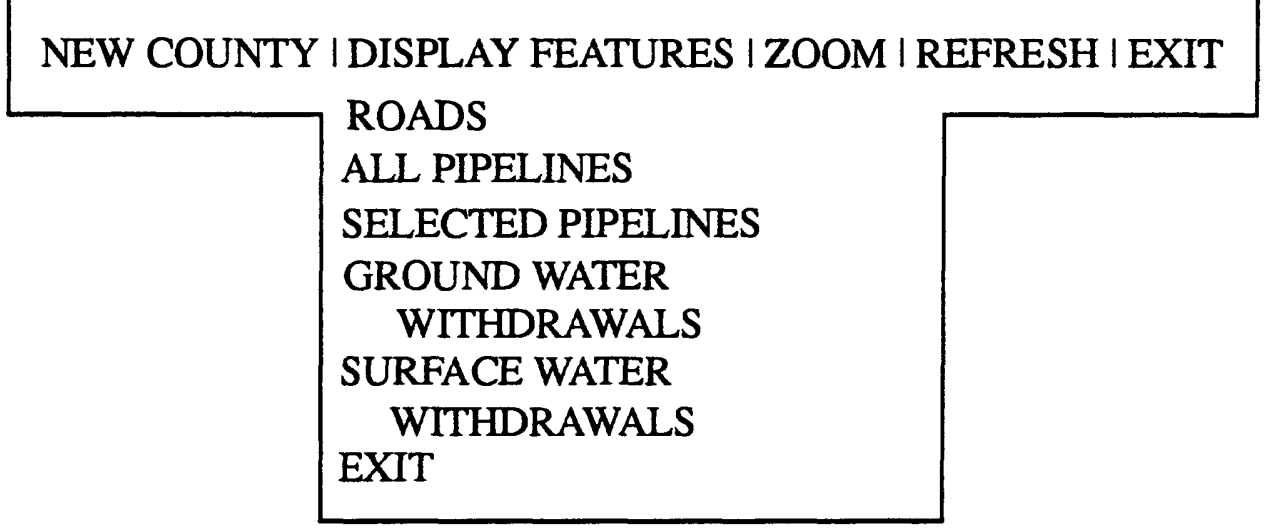

In another type of menu the choices are arranged vertically inside a box. These may be presented in one or in several columns. The first line is the title and every line thereafter represents a menu selection or choice. The Main menu, shown below, is an example of this type.

--- RURAL WATER DELIVERY NETWORK ---
DISPLAY DELIVERY SYSTEM FEATURES
CREATE/UPDATE PIPELINE COVERAGES
CREATE WITHDRAWAL COVERAGES
QUIT

The third type of menu used is a form menu. This menu has a title line and may have several lines that display information. The words or phrases that represent menu selections may appear anywhere within the menu box and several selections may appear on the same line. This type of menu is unique because the user may interact with the menu by typing a response. An example of this menu is shown below, in which a default pathname is listed at the top of the menu, followed by a brief set of instructions. Following the phrase "Coverage name:", the default pathname is written again. This default may be accepted or overwritten.

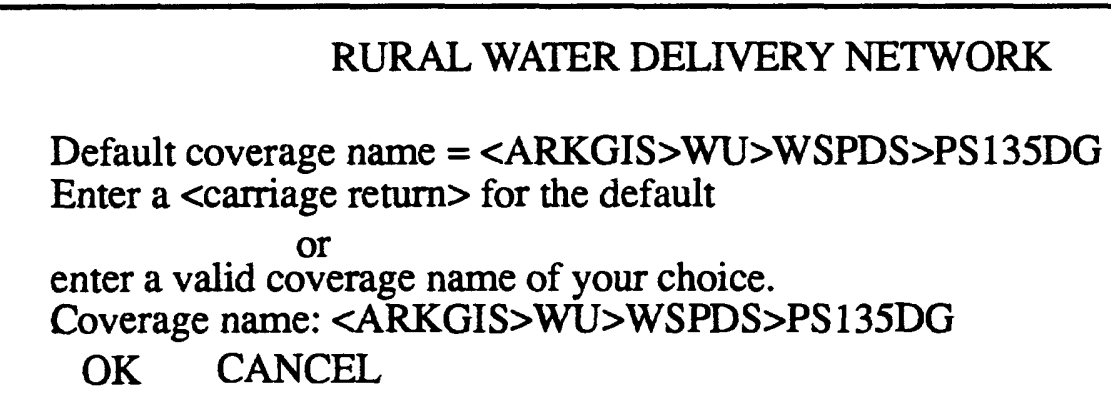




\section{ACCESSING THE RURAL WATER-DELIVERY NETWORK GEOGRAPHIC INFORMATION SYSTEM (GIS) SOFTWARE}

Initial entry into the Rural Water-Delivery Network GIS software is gained by first entering into ARC/INFO by typing ARC at the system prompt. After a short pause, a banner will appear on the screen followed by the prompt "Arc:." At the prompt, enter RWDN.

OK, ARC

(C) 1988 - 1990 Environmental Systems Research Institute, Inc.

All Rights Reserved Worldwide

ARC Version 5.0.1

Arc: RWDN

After a few seconds, the screen will clear and the Main menu will appear in the middle of the screen.

$$
\begin{aligned}
& \text {--- RURAL WATER DELIVERY NETWORK --- } \\
& \text { DISPLAY DELIVERY NETWORK FEATURES } \\
& \text { CREATE/UPDATE PIPELINE COVERAGES } \\
& \text { CREATE WITHDRAWAL COVERAGES } \\
& \text { QUIT }
\end{aligned}
$$

The title of the menu is shown on the first line, followed by four different selections. The first menu choice, DISPLAY DELIVERY NETWORK FEATURES, will be highlighted. The user may now pick any menu choice. Each choice on the Main menu, except the last one, represents a main section of the software and will be discussed individually. The last choice, QUIT, exits the system and returns the user to the system prompt. All of the menus and submenus have a choice that allows the user to exit the menu without any action being taken. These choices will be labeled either QUIT, EXIT, or CANCEL.

\section{DISPLAY DELIVERY NETWORK FEATURES}

When the choice, DISPLAY DELIVERY NETWORK FEATURES, is selected, the screen will be erased and the County Selection menu (fig. 1) will be displayed. During the interval between the pick from the Main menu and the appearance of the County Selection menu, initialization procedures may cause a slight time lag. The County Selection menu displays the names of all the counties in Arkansas and each county's Federal Information Processing Standards (FIPS) codes. Any county may be selected or the user may exit the menu and return to the Main menu by selecting EXIT. After a county has been picked, the menu will be erased from the screen. Again, initialization procedures will cause a slight time lag. The selected county 


$\begin{array}{llll}\text { 001-ARKANSAS } & \text { 003-ASHLEY } & \text { 005-BAXTER } & \text { 007-BENTON } \\ \text { 009-BOONE } & \text { 011-BRADLEY } & \text { 013-CALHOUN } & \text { 015-CARROLL } \\ \text { 017-CHICOT } & \text { 019-CLARK } & \text { 021-CLAY } & \text { 023-CLEBURNE } \\ \text { 025-CLEVELAND } & \text { 027-COLUMBIA } & \text { 029-CONWAY } & \text { 031-CRAIGHEAD } \\ \text { 033-CRAWFORD } & \text { 035-CRITTENDEN } & \text { 037-CROSS } & \text { 039-DALLAS } \\ \text { 041-DESHA } & \text { 043-DREW } & \text { 045-FAULKNER } & \text { 047-FRANKLIN } \\ \text { 049-FULTON } & \text { 051-GARLAND } & \text { 053-GRANT } & \text { 055-GREENE } \\ \text { 057-HEMPSTEAD } & \text { 059-HOT SPRING } & \text { 061-HOWARD } & \text { 063-INDEPENDENCE } \\ \text { 065-IZARD } & \text { 067-JACKSON } & \text { 069-JEFFERSON } & \text { 071-JOHNSON } \\ \text { 073-LAFAYETTE } & \text { 075-LAWRENCE } & \text { 077-LEE } & \text { 079-LINCOLN } \\ \text { 081-LITTLE RIVER } & \text { 083-LOGAN } & \text { 085-LONOKE } & \text { 087-MADISON } \\ \text { 089-MARION } & \text { 091-MILLER } & \text { 093-MISSISSIPPI } & \text { 095-MONROE } \\ \text { 097-MONTGOMERY } & \text { 099-NEVADA } & \text { 101-NEWTON } & \text { 103-OUACHIA } \\ \text { 105-PERRY } & \text { 107-PHILLIPS } & \text { 109-PIKE } & \text { 111-POINSETT } \\ \text { 113-POLK } & \text { 115-POPE } & \text { 117-PRAIRIE } & \text { 119-PULASKI } \\ \text { 121-RANDOLPH } & \text { 123-ST FRANCIS } & \text { 125-SALINE } & \text { 127-SCOTT } \\ \text { 129-SEARCY } & \text { 131-SEBASTIAN } & \text { 133-SEVIER } & \text { 135-SHARP } \\ \text { 137-STONE } & \text { 139-UNION } & \text { 141-VAN BUREN 143-WASHINGTON } \\ \text { 145-WHITE } & \text { 147-WOODRUFF } & \text { 149-YELL } & \text { Exit Menu }\end{array}$

Figure 1.--County selection menu. 
boundary will then be drawn on the screen along with the county name. An example of this, using Arkansas County, is shown in figure 2 . After the county boundary and county name are drawn, the pull-down Display menu will appear at the top of the screen.

\section{New County}

\section{NEW COUNTY I DISPLAY FEATURES I ZOOM I REFRESH | EXIT}

When the NEW COUNTY option is selected from the Display menu, the screen will clear and the County Selection menu will appear on the screen. The user may then pick a new county.

\section{Display Features}

When the DISPLAY FEATURES option is selected from the Display menu, a submenu will appear below the DISPLAY FEATURES option.

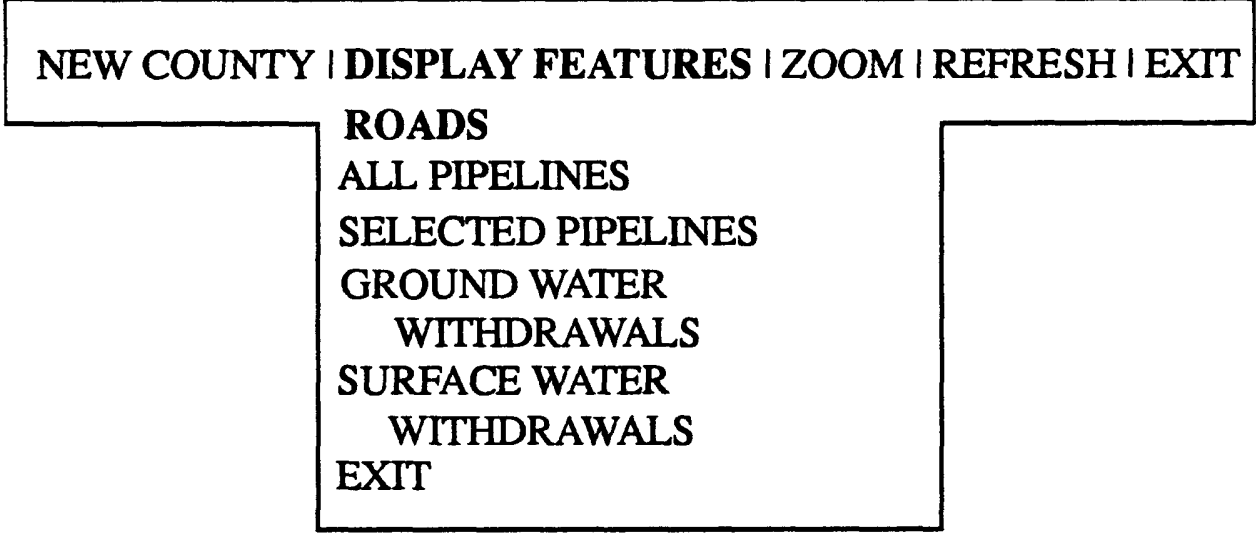

When a feature from the submenu is picked, with the exception of the EXIT option, the terminal screen will clear and the selected feature, along with any other feature that was already present, will be drawn on the screen. The features are drawn in a certain sequence so that all the selected features will have maximum visibility. For example, when ROADS is the selected feature, the screen will clear and the roads network for the county will be the first feature drawn to the terminal screen even if other features, such as pipelines or withdrawal points have already been drawn. This is done because the roads network is a background coverage to be used mainly for reference. If the roads network were drawn last, other features might be overlain and would not be visible. 

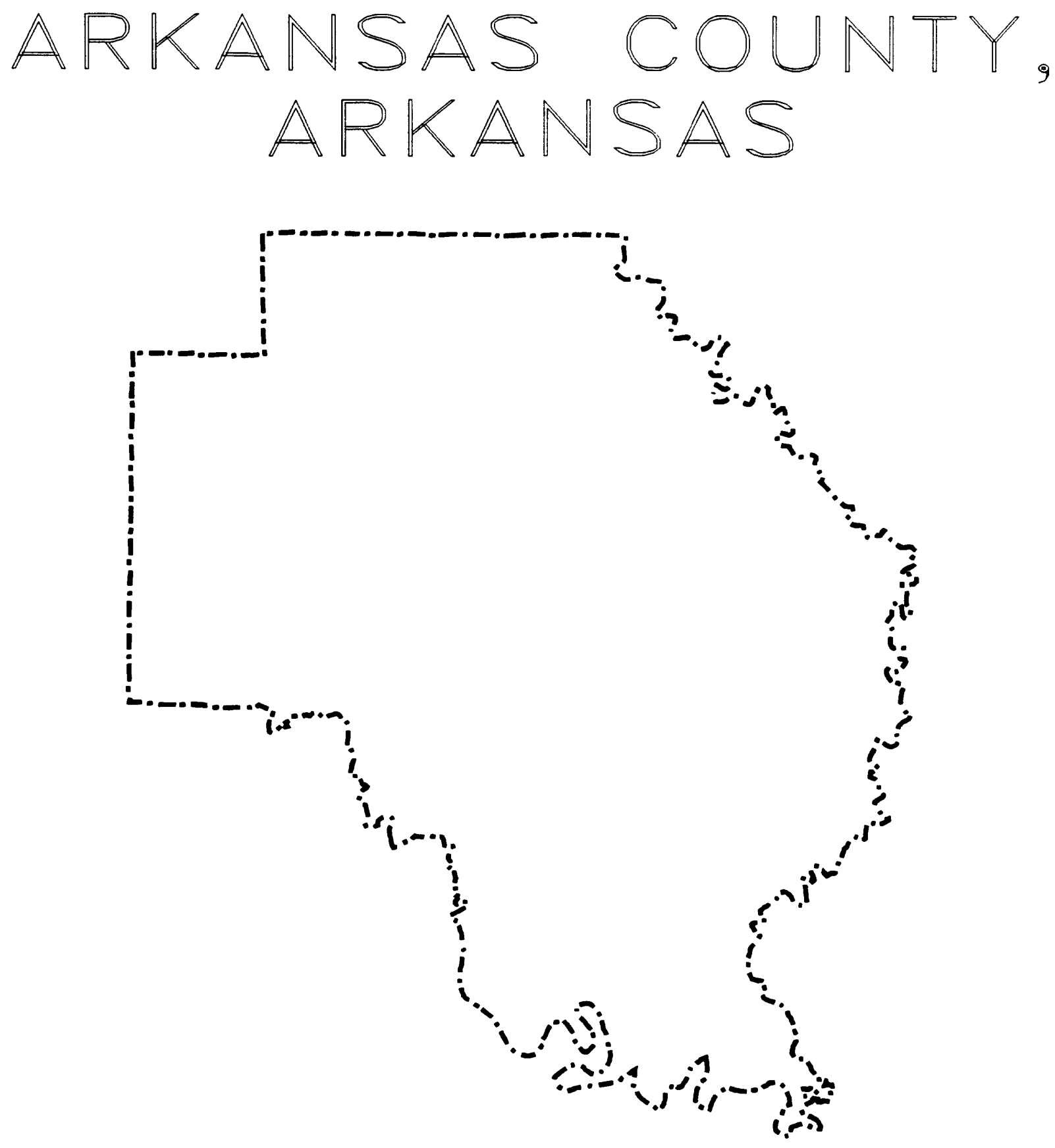

Figure 2.--Computer terminal display of Arkansas County boundary resulting from selection of Arkansas County from the County Selection menu. 


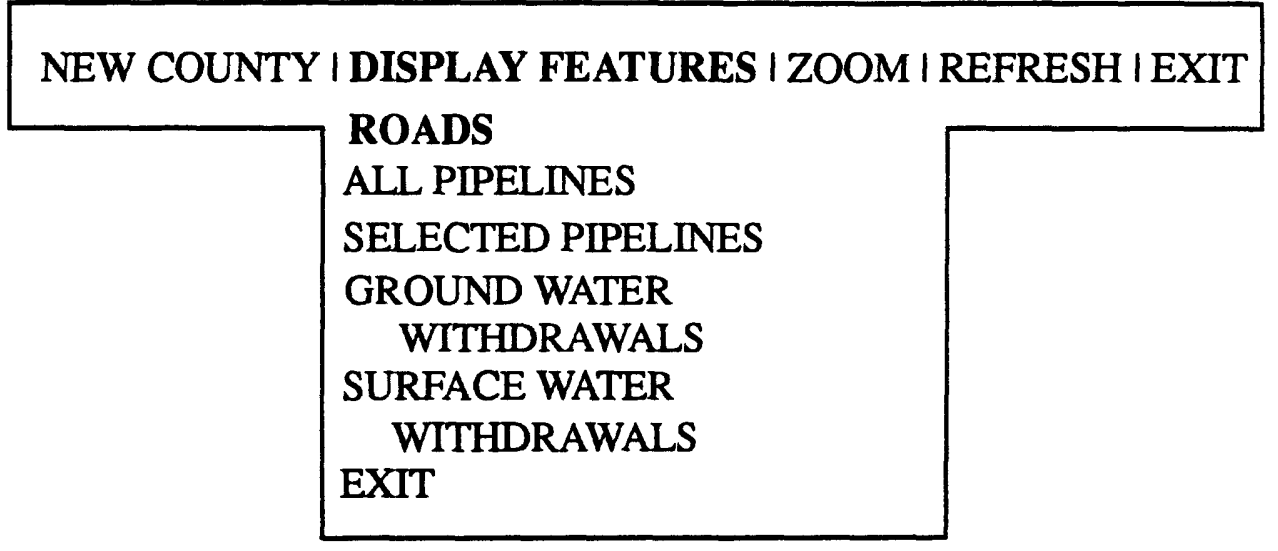

The first selection of the Display Features submenu, ROADS, will draw all of the roads in the county in a light gray color. This option is used primarily to provide a background or reference against which to display the pipelines and withdrawal points. This selection can take several minute to display on the screen.

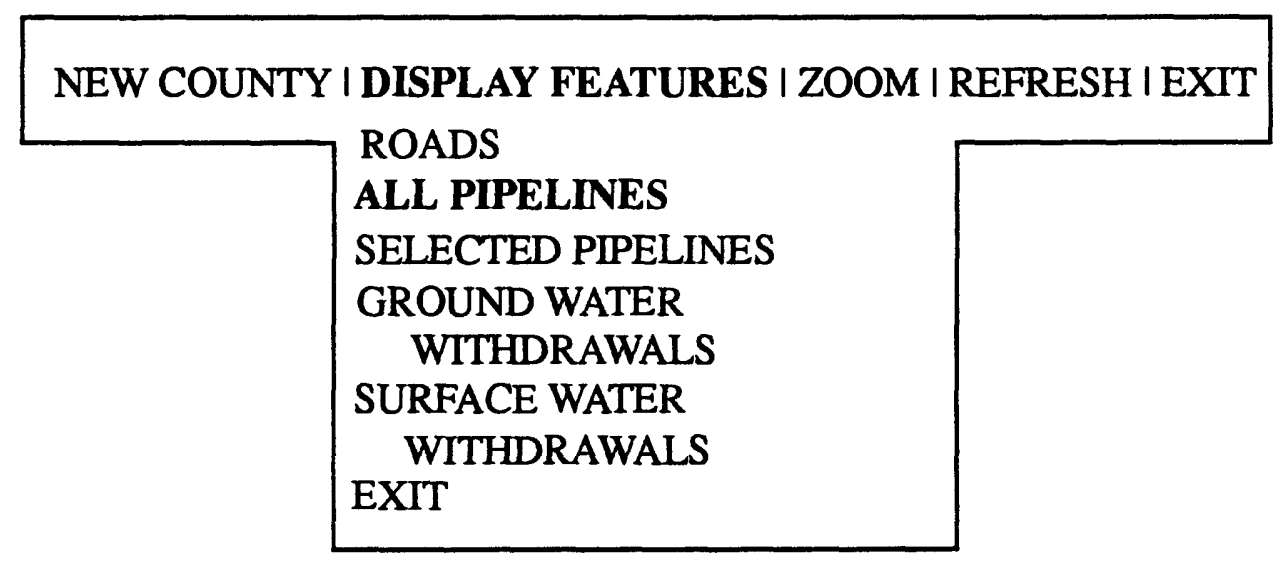

The next selection in the Display Features submenu, ALL PIPELINES, will display all of the rural water-delivery pipelines on the screen along with a color-coded explanation. Different diameters of pipelines are displayed using a combination of colors and line widths. Pipeline diameters can range from 2 to 48 inches ( 50.8 to $1,219.2$ millimeters) but there are only six colors available. Some counties have a wide range of pipeline sizes, and one color may represent more than one diameter. In these cases, the line width will differentiate between the different sizes. Lines representing pipelines of many different sizes commonly may crowd into a small area on the screen. In such cases, line widths may be difficult to differentiate. For these situations, the ZOOM option (described in another section) may be appropriate. When a county without pipelines is selected, a message will appear, and after a short pause, the Display Features menu will appear. 


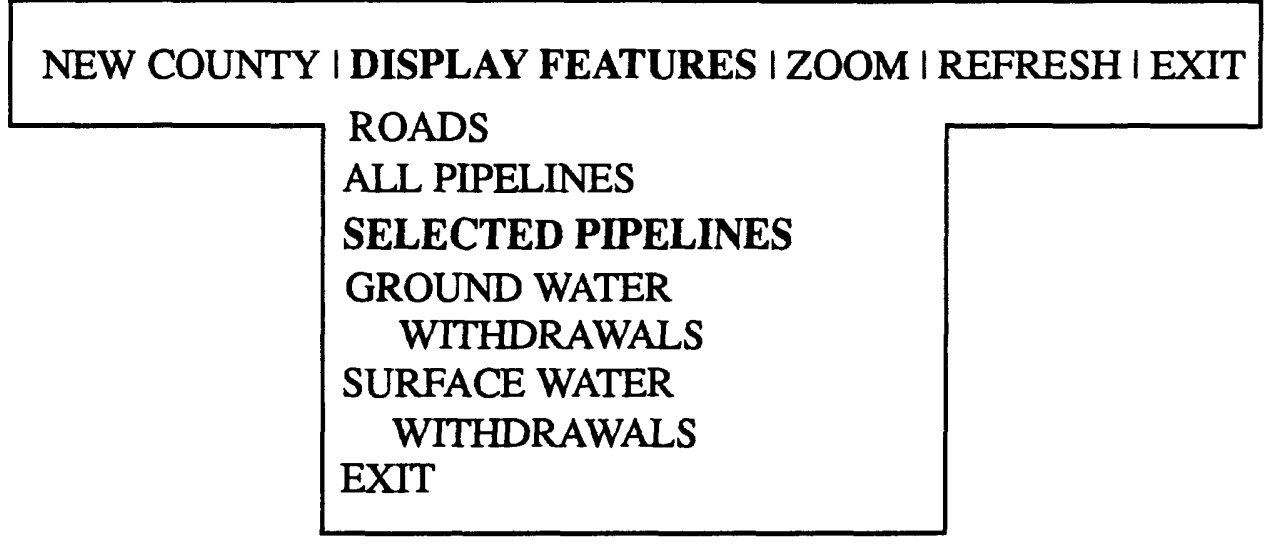

Choosing the SELECTED PIPELINES option from the Display Features submenu allows the user to select pipelines of specific diameters for viewing. The screen will clear and a menu, like the one shown below, will appear with a list of the diameters of pipelines for the selected county.

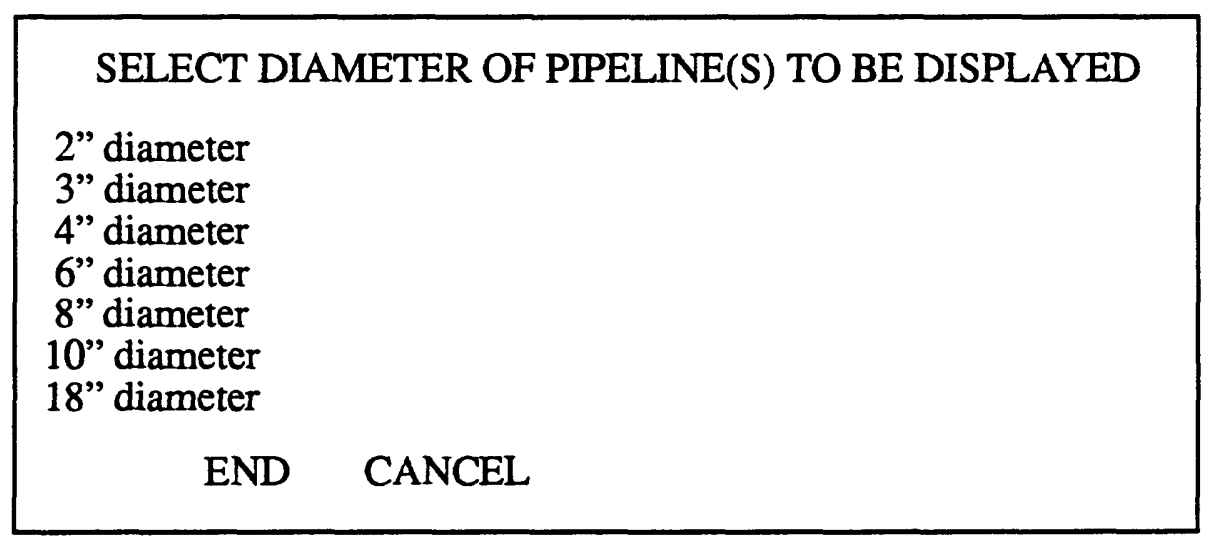

This menu is created specifically for the selected county and will display only those pipeline diameters that are present in that particular county. The user may select one or more of these pipeline diameters by positioning the cursor over the selection and picking it. When finished with the selection, the user should position the cursor over END and pick it. To exit the menu without making a selection, CANCEL should be selected. After END is picked, the screen will clear and the selected pipelines will be drawn on the screen along with a color-coded explanation that will show all of the available diameters, not just the ones selected. 


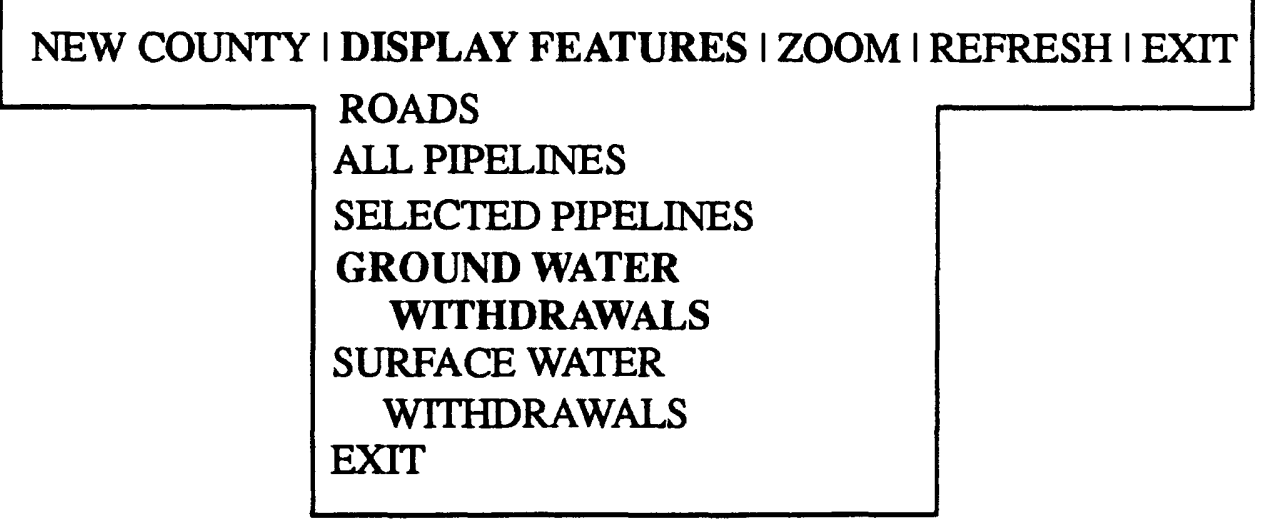

The next two selections, GROUND WATER WITHDRAWALS and SURFACE WATER WITHDRAWALS, will display public supply and municipal withdrawal points for the selected county. The ground-water points are displayed as a green asterisk and the surface-water points are displayed as a blue asterisk. If no withdrawal points exist for the selected category, a message will be written on the screen. In some counties, a few withdrawal points will be displayed outside the county boundary. This is most commonly caused by an error in the reported latitude and longitude.

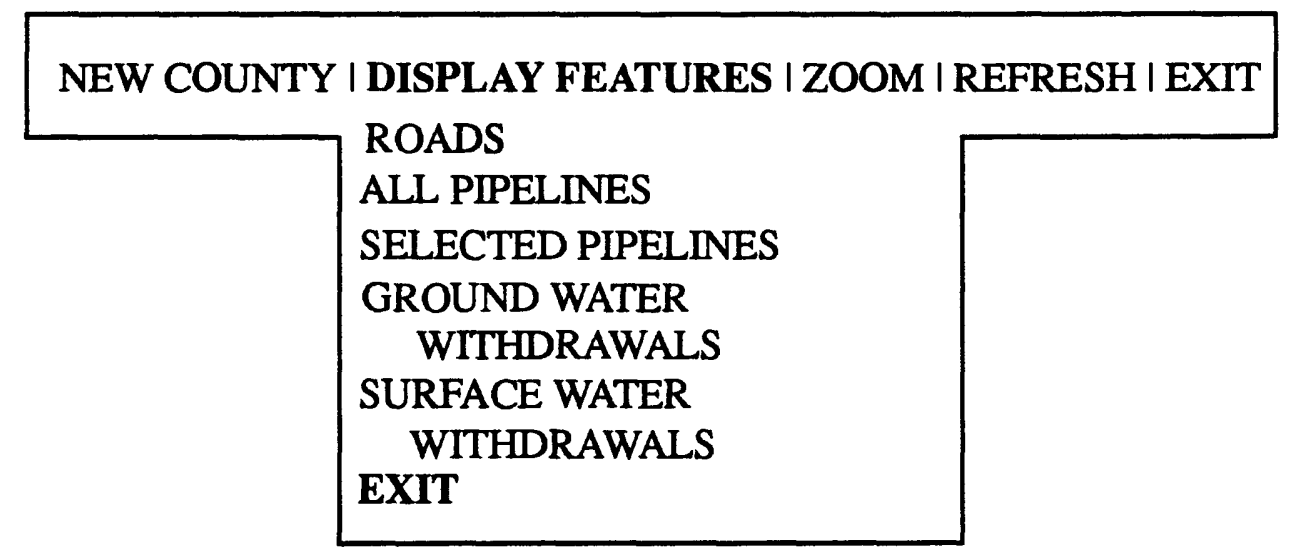

The final option, EXIT, allows the user to exit from this submenu without making any active choice. When EXIT is picked, the Display menu will reappear on the screen. 


\section{NEW COUNTY I DISPLAY FEATURES I ZOOM I REFRESH I EXIT}

The ZOOM selection of the Display menu allows the user to zoom in on a specific area for more detailed viewing. When the ZOOM feature is selected from the menu, a pull-down submenu will appear below the ZOOM choice.

NEW COUNTY I DISPLAY FEATURES I ZOOM I REFRESH I EXIT

IN

When the IN option is selected, the menu will be cleared from the screen, the cursor crosshairs will appear, and the following line will appear at the top of the screen:

\section{"Enter lower left corner of the zoom box"}

Using the mouse, the user must then move the crosshairs to a position that coincides with the lower left corner of the area that is to be enlarged. When the cursor is positioned correctly, press one of the mouse buttons. When this is done, another line will appear at the top of the screen.

\section{"Enter upper right corner of the zoom box"}

Again using the mouse, the user will follow the same procedure as outlined above except that the upper right comer of the area will be selected. When this has been done, the screen will clear and the selected portion of the map will be drawn to the graphics area on the screen. The graphics area on the screen is not the full screen. This area is slightly smaller than the full screen and leaves room along the top and the right side for titles and explanations to be drawn. Any explanations that were present will be redrawn, and the Display menu will appear at the top of the screen.

To redraw the full map, select the ZOOM option and then select the OUT option from the submenu. The screen will clear and the entire map and any accompanying explanations will be redrawn on the screen and the Display menu will reappear.

The ZOOM feature just described is called a software zoom. This is because it is enabled by software routines incorporated into the system. This type of zoom is hardware independent, which means that it will work with any terminal type that is supported by the ARC/INFO software. The other type of zoom is called a hardware zoom. This is terminal specific and is accomplished by the use of special keys on the terminal. A hardware zoom typically is more functional than a software zoom and is usually quicker. If a terminal has hardware zoom capability, the user may select the hardware zoom instead of the zoom feature provided on the menu. 


\section{Refresh}

\section{NEW COUNTY | DISPLAY FEATURES | ZOOM | REFRESH | EXIT}

The REFRESH option clears the terminal screen and redraws the currently selected elements to the screen. This feature can be used whenever unwanted elements appear on the screen, such as messages from another user.

\section{Exit}

\section{NEW COUNTY I DISPLAY FEATURES I ZOOM I REFRESH | EXIT}

Selecting the EXIT option will cause the terminal screen to clear and the Main menu will return to the screen.

--- RURAL WATER DELIVERY NETWORK ---

DISPLAY DELIVERY SYSTEM FEATURES

CREATE/UPDATE PIPELINE COVERAGES

CREATE WITHDRAWAL COVERAGES

QUIT

\section{CREATE/UPDATE PIPELINE COVERAGES}

The second choice from the Main menu, CREATE/UPDATE PIPELINE COVERAGES, allows the user to create or update pipeline coverages. It is strongly recommended that users creating or updating pipeline coverages have some experience with ARC/INFO. The software that has been written for the procedures that are described in this section, simplify and standardize many of the ARC/INFO functions that are utilized, but these procedures still need to be performed by a user who has some ARC/INFO experience. 


\section{Naming Conventions}

Certain conventions are used in naming the pipeline coverages. All new coverage names are composed of three elements: (1) a prefix of PS, (2) the county FIPS code, and (3) a suffix of DG which indicates that the coverage is being digitized. For example, the pipeline coverage for Sharp County, which has a FIPS code of 135, would be named PS135DG. When the coverage is finished and verified, the name of the pipeline coverage changes to a prefix of PS followed by a period and the county FIPS code. Continuing the example from above, the coverage for Sharp County would change from PS135DG to PS.135. Although naming conventions are the default, the user is given the opportunity to override the default with a different coverage name. This presents no problem if the user remembers that the final coverage must be named following the conventions outlined above and must be located in the default directory in order to be accessed by the software.

\section{Create a New Pipeline Coverage}

When the CREATE/UPDATE PIPELINE COVERAGES selection is made from the Main menu, the screen clears and the County Selection menu appears. Following selection of the county, the Coverage Automation menu appears on the screen.

COVERAGE AUTOMATION MENU
CREATE A NEW PIPELINE COVERAGE
UPDATE A PIPELINE COVERAGE
CLEAN A PIPELINE COVERAGE
BUILD \& RENUMBER COVERAGE
POPULATE DIAMETER VARIABLE
EXIT

The first choice, CREATE A NEW PIPELINE COVERAGE, initiates the process of creating a new pipeline coverage by clearing the screen and displaying the Coverage Selection menu. 


\begin{tabular}{|l|}
\hline RURAL WATER DELIVERY NETWORK \\
Default coverage name $=<$ ARKGIS $>$ WU $>$ WSPDS $>$ PS $135 D G$ \\
Enter a $<$ carriage return $>$ for the default \\
or \\
enter a valid coverage name of your choice. \\
Coverage name: $<$ ARKGIS $>$ WU $>$ WSPDS $>$ PS135DG \\
OK CANCEL
\end{tabular}

When the menu is displayed, the cursor is located on the highlighted default coverage name following the line title "Coverage name:." To accept the default coverage name, simply pick the choice labeled OK. To enter a new coverage name, type a valid pathname for the new coverage, enter a carriage return, and again pick the choice labeled $\mathrm{OK}$. If the user is not satisfied with the selection or if the user wishes to exit the menu with no action being taken, he or she may pick the choice labeled CANCEL. If CANCEL is picked, the Coverage Automation menu will reappear on the screen.

When the coverage name has been chosen, the screen will clear and a message will appear stating that the coverage is being created. After a short period of time, the screen will again clear and all of the roads for the county will be drawn. When all of the roads have been drawn, the following query will appear:

"Do you want to highlite a highway? <cr>=Y:"

This requires a response from the keyboard of either a carriage return or of a " $y$ ", "Y", "yes", "Yes", or "YES" to answer in the affirmative or a "n", "N", "no", "No", or "NO" for a negative response. If an affirmative answer is given, the user is prompted to enter a highway number. This number corresponds to the number of the State or Federal highway or interstate being highlighted. For example, to highlight State Highway 101, enter "101". To highlight Interstate 40, enter "40". After a number has been given, that highway will be redrawn in yellow. The user may highlight as many roads or highways as he chooses. This can make the addition of pipelines easier because pipelines usually follow roads or highways. After this step is completed, or if a negative response was given to the query, the county boundary is drawn and the following message is printed before the user begins adding pipelines:

Enter \&RETURN when ready to return to the menu.

To insure that the software performs as designed and to maintain the integrity of the data, it is important for the user to remember that the only correct way to exit from this session is to enter \&RETURN at the prompt "Arcedit:." 
After pausing for several seconds while the above message is displayed, the screen will clear and the Add menu (see below) will appear and automation of the pipelines can begin.

Options

1) Vertex

2) Node

3) Curve

4) Delete vertex

5) Delete arc

6) Spline on/off

7) Square on/off

8) Digitizing Options

9) Quit

\section{(Line) Usr-ID: $1 \quad$ Points 0}

The coordinate device specified by the software is the mouse that has only three keys (1-3) as opposed to a keypad on a digitizer that has ten keys (0-9). The left-hand key on the mouse is 1 , the middle key is 2 , and the right-hand key is 3 . This means that when using the mouse, only the first three options on the ADD menu can be accessed. This presents no problem when adding arcs since the two keys used for that operation are the 1 and 2 keys, but it means that options 4 through 9 on the menu are inaccessible to the user. The functions listed by menu options 4 through 9 can be performed by exiting from the menu and entering commands from the keyboard. Remember, at this point the user is in a regular ARCEDIT session so an exit from the ADD menu will return the ARCEDIT prompt, "Arcedit:." From this prompt any valid ARCEDIT commands may be entered from the keyboard. To exit the menu, enter any key from the keyboard followed by a carriage return. The program at this point is expecting all input to come from the mouse, which is the coordinate device specified. It treats input from any other source, like the keyboard, as an error. Thus, the error message, "Error reading cursor location" will appear, the terminal will beep, and the ADD procedure will terminate if a keyboard entry is made. The user should ignore the error message and continue. To terminate the session, enter \&RETURN at the Arcedit prompt. The screen will clear, and a message will appear asking the user if the changes are to be saved:

\section{Do you want to save your changes $(<\mathrm{cr}\rangle=\mathrm{Y})$ ?}

An affirmative answer will save all changes or additions made to the coverage and a negative answer will exit without saving any additions or changes. The Coverage Automation menu will then appear on the screen.

\section{Undate a Pipeline Coverage}

COVERAGE AUTOMATION MENU
CREATE A NEW PIPELINE COVERAGE
UPDATE A PIPELINE COVERAGE
CLEAN A PIPELINE COVERAGE
BUILD \& RENUMBER COVERAGE
POPULATE DIAMETER VARIABLE
EXIT

The second option on the Coverage Automation menu is UPDATE A PIPELINE COVERAGE. Selection of this choice will produce a result similar to selection of the first choice, CREATE A NEW PIPELINE COVERAGE. The Coverage Selection menu will be displayed, the 
roads and highways for the county will be drawn, and the option to highlight a road or highway will be given. Following display of the roads and highways, all pipelines present in the coverage also are drawn. The following message is printed on the screen to remind the user of the correct way to exit the update session:

Enter \&RETURN when ready to return to the menu.

After the message has been displayed, the user will be in an ARCEDIT session with the prompt, "Arcedit:," on the screen. From this point any ARCEDIT commands may be used to change or update the coverage. When the user exits the session by entering \&RETURN at the prompt, he or she will have the choice of saving any changes or additions to the coverage or not saving changes or additions. After exiting from the session, the screen will clear and the Coverage Automation menu will appear.

\section{Clean a Pipeline Coverage}

COVERAGE AUTOMATION MENU
CREATE A NEW PIPELINE COVERAGE
UPDATE A PIPELINE COVERAGE
CLEAN A PIPELINE COVERAGE
BUILD \& RENUMBER COVERAGE
POPULATE DIAMETER VARIABLE
EXIT

The third selection from the Coverage Automation menu is CLEAN A PIPELINE COVERAGE. This selection should be executed after the digitization process is complete because it performs the ARC/INFO operation CLEAN on the coverage. This operation "cleans" the coverage by removing small arcs caused by overshoots in the digitizing process. This menu selection also adds the pipeline diameter attribute to the coverage's internal attribute table. The Clean Cover Selection menu, shown below, is displayed and shows the default names for both the input coverage and the final output coverage.

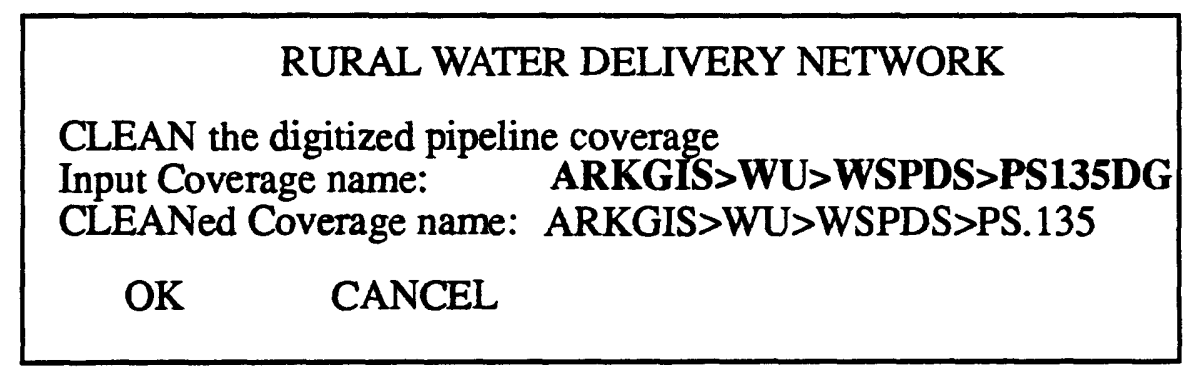

Although the final output coverage name may be changed, it must be remembered that the software cannot access any coverage that is not stored in the proper directory or does not have a name that follows the naming conventions discussed at the beginning of this section. When the input and output coverage names are satisfactory, the OK is picked and the ARC/INFO process 
CLEAN is performed on the input coverage with the result being written to the output coverage. Ideally, the digitized coverage should only go through the CLEAN process once. If a coverage goes through the CLEAN process too many times, the features may become distorted. When the CLEAN process is completed, the Coverage Automation menu is displayed on the screen.

\section{Build \& Renumber Coverage}

COVERAGE AUTOMATION MENU
CREATE A NEW PIPELINE COVERAGE
UPDATE A PIPELINE COVERAGE
CLEAN A PIPELINE COVERAGE
BUILD \& RENUMBER COVERAGE
POPULATE DIAMETER VARIABLE
EXIT

When a pipeline coverage has been updated or altered in some way subsequent to the initial CLEAN process, the fourth option from the Coverage Automation menu, BUILD \& RENUMBER COVERAGE, should be selected. Selection of this option runs the ARC/INFO BUILD and RENUMBER functions, which rebuild the coverage feature attribute tables. After this selection is picked, the screen clears and the Coverage Selection menu is displayed. The default name used is the final version of the coverage name, a prefix of PS. followed by the county FIPS code as shown in the example below.

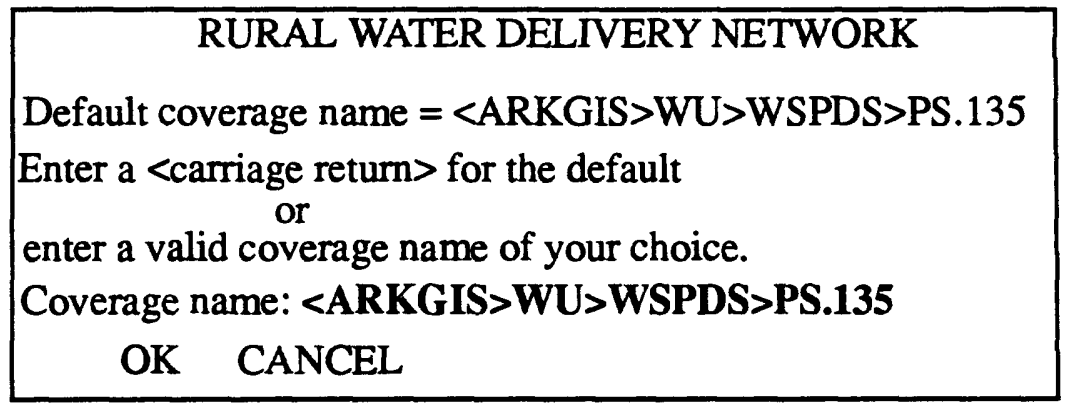

Once the correct coverage name has been determined, pick OK. The menu will be cleared from the screen and replaced by a message that the coverage is being built and renumbered. When the process has finished, the screen will clear and the Coverage Automation menu will be displayed. 


\section{Populate Diameter Variable}

COVERAGE AUTOMATION MENU
CREATE A NEW PIPELINE COVERAGE
UPDATE A PIPELINE COVERAGE
CLEAN A PIPELINE COVERAGE
BUILD \& RENUMBER COVERAGE
POPULATE DIAMETER VARIABLE
EXIT

The menu selection POPULATE DIAMETER VARIABLE initiates the process that allows the user to assign pipeline diameters for a coverage. After this selection has been picked, the screen clears and the Select Coverage menu is displayed. The default coverage name displayed is the final version of the coverage name, PS. followed by the county FIPS code.

\begin{tabular}{|c|}
\hline RURAL WATER DELIVERY NETWORK \\
Default coverage name $=<$ ARKGIS $>$ WU $>$ WSPDS $>$ PS. 135 \\
Enter a $<$ carriage return $>$ for the default \\
or \\
enter a valid coverage name of your choice. \\
Coverage name: $<$ ARKGIS $>$ WU $>$ WSPDS $>$ PS.135 \\
OK CANCEL
\end{tabular}

When the coverage name has been determined, the screen will clear, and the pipeline coverage will be displayed with the Select menu on the screen.

SELECT ONEISELECT MANYISELECT ALLIQUIT \& SAVE CHANGESIQUIT \& NOSAVE

These menu options represent ARCEDIT commands and allow the user to select one or more pipelines with the same diameter. Next, the Select Diameter menu will be displayed. This menu shows all common pipe diameters used in pipeline construction. 


\begin{tabular}{|c|}
\hline SELECT DIAMETER \\
$2 "$ \\
$3 "$ \\
$4 "$ \\
$5 "$ \\
$6 "$ \\
$7 "$ \\
$8 "$ \\
$9 "$ \\
$10 "$ \\
$12 "$ \\
$14 "$ \\
$16 "$ \\
$18 "$ \\
$20 "$ \\
$22 "$ \\
$24 "$ \\
$36 "$ \\
$48 "$ \\
Cancel \\
\hline
\end{tabular}

The diameter attribute for the pipeline or pipelines selected will be set equivalent to the diameter selected from the menu. The pipeline or pipelines will then be redrawn in a color unique to that diameter. When exiting, the user has the option of saving all changes and updates or continuing without saving them. After exiting, the Coverage Automation menu is displayed.

COVERAGE AUTOMATION MENU
CREATE A NEW PIPELINE COVERAGE
UPDATE A PIPELINE COVERAGE
CLEAN A PIPELINE COVERAGE
BUILD \& RENUMBER COVERAGE
POPULATE DIAMETER VARIABLE
EXIT

The final option, EXIT, will return the Main menu to the screen. 


\section{CREATE WITHDRAWAL COVERAGES}

The third option on the Main menu, CREATE WITHDRAWAL COVERAGES, initiates a two-step process that (1) retrieves water-use data from the WUDS data base and (2) uses the retrieved water-use data to create public and municipal water supply withdrawal coverages. There are eight data items that are retrieved from the WUDS data base and included in the withdrawal coverages as attributes. These data items are listed in the following table along with their item names.

$\begin{array}{ll}\text { WUDS data item } & \text { Item name } \\ \text { Water user number } & \text { WUNUM } \\ \text { Water user name } & \text { WUNAME } \\ \text { Street address } & \text { STREET } \\ \text { City } & \text { CITY } \\ \text { State } & \text { STATE } \\ \text { Zip } & \text { ZIP } \\ \text { Measurement point ID } & \text { MPID } \\ \text { Annual amount withdrawn } & \text { ANLAMNT }\end{array}$

This software system makes no provisions for accessing the individual withdrawal sites and listing any of the attributes, but this may be done independent of this system.

The water-use data stored in WUDS represent discrete points from which water is withdrawn from either ground- or surface-water sources and used for public supply. Data are reported to the USGS on an annual basis by local agencies, such as water districts or municipalities. Data are collected for the water year (October through September) and usually are recorded and stored in the WUDS data base during the first 6 months of the following water year.

The menu option CREATE WITHDRAWAL COVERAGE should be run annually following the completion of the WUDS update. The menu also may be run throughout the year if special circumstances warrant it. Repeated use of this option during the year will only result in a waste of computer-system resources because it would result in the coverages being recreated with the same data. 
After selection of the CREATE WITHDRAWAL COVERAGES option from the Main menu, the terminal screen is cleared and the Withdrawal Retrieval menu is presented.

\begin{tabular}{|c|}
\hline WITHDRAWL RETRIEVAL MENU \\
RURAL WATER DELIVERY NETWORK \\
RETRIEVE DATA FOR: \\
FIPS COde COUNTY \\
RETRIEVE FOR WATER YEAR 1989 \\
ONE COUNTY \\
ALL COUNTIES \\
OK CANCEL \\
\hline
\end{tabular}

At this point the date may be changed if the date displayed on the menu is not the water year desired.

The user then selects whether the data are to be retrieved for one county or for all counties in the State. If the option ONE COUNTY is picked, the screen will clear and the County Selection menu will appear. After a county has been selected, the Withdrawal Retrieval menu is again presented on the screen with the FIPS code and the county name for the selected county. The menu shown below uses Ouachita County as an example. If the option ALL COUNTIES is picked, the word ALL will be listed under the heading FIPS code

WITHDRAWL RETRIEVAL MENU
RURAL WATER DELIVERY NETWORK
RETRIEVE DATA FOR:
FIPS Code
103
COUNTY
OUACHITA
RETRIEVE FOR WATER YEAR 1989
ONE COUNTY
ALL COUNTIES
OK CANCEL


If the selection is satisfactory, the user picks OK. If the selection is unsatisfactory, the user can return to the Main menu by picking CANCEL.

From this point on, the retrievals from the WUDS data base and the creation of the ARC/ INFO coverages will be done as a batch job, which minimizes impact on computer-system resources. Batch jobs run on the computer system at a low priority. If ALL COUNTIES are selected, the batch jobs are automatically run at night when there are fewer demands on the computational resources. If ONE COUNTY is selected, the user may select the batch queue from the Batch Queue menu, which lists all of the batch queues available on the computer system.

\begin{tabular}{|cc|}
\hline \multicolumn{2}{|c|}{ - BATCH QUEUE SELECTION MENU -- } \\
DAYTIME QUEUES & NIGHTTIME QUEUES \\
LARGE & NIGHT.1 \\
LARGE.1 & NIGHT.2 \\
LARGE.2 & \\
LARGE.3 & \\
OK & CANCEL \\
\hline
\end{tabular}

The batch queues listed in the Batch Queue Selection menu are divided between daytime and nighttime queues. Jobs that consume large quantities of computer-system resources should be run on one of the nighttime queues so the effects (inconvenience to) on other users will be minimized. Smaller jobs can be run on one of the daytime queues.

After a batch queue is picked, the screen will clear and the message "... Creating Batch Jobs to Retrieve Data \& Create Coverages" will be displayed while the jobs are being submitted to the batch queue. After the batch jobs have been submitted, the Main menu will again appear on the screen.

\section{SUMMARY}

The Rural Water Delivery Network Geographic Information System (GIS) is composed of spatial data and of software routines. The spatial data are stored in several data layers, called coverages. The data consist of a pipeline coverage and a coverage of municipal and public watersupply withdrawal points for each county in the State. The software is accessed by the user through a series of menus that appear on the terminal screen. Selections from these menus are made with the mouse attached to the terminal or with the carriage return key. The main menu categories allow the user to display, create, or update the spatial data in the Rural Water Delivery Network GIS. 